\title{
Induction of sexual reproduction in Spirogyra clones - does an universal trig- ger exist?
}

\author{
Melanie Zwirn ${ }^{1}$, Charlotte CHEN $^{1}$, Bohuslav Uher ${ }^{1,2} \&$ Michael SCHAGERL $^{2 *}$ \\ ${ }^{1}$ University of Vienna, Department Limnology, Althanstraße 14, A-1090 Vienna, Austria; * Corresponding author \\ e-mail:michael.schagerl@univie.ac.at \\ ${ }^{2}$ Masaryk University, Department of Botany and Zoology, Kotlářská 2, 61137 Brno, Czech republic
}

\begin{abstract}
Species identification of the ubiquitous green algae genus Spirogyra Link based on the traditional morphological species concept requires sexual reproduction stages including ripe hypnozygotes. Since these stages are only infrequently observed in nature, an artificial onset of the sexual phase in the laboratory would be most welcome. We therefore tried to induce conjugation in 95 strains of Spirogyra originating from various European sampling localities. A linear discriminant analysis based on a comparison of abiotic field data between sites with vegetative and conjugating filaments indicated that nitrate deprivation together with elevated organic compounds of $\mathrm{N}$ and $\mathrm{P}$ promotes conjugation. In the laboratory, altogether 681 experimental setups were conducted with a focus on variation of nutrient supply and irradiance conditions. No general trigger could be found promoting sexual reproduction in the genus, but the importance of certain nutrient ratios according to specific ecological demands seems likely. Besides nitrate depletion, also red, green and white light sometimes yielded in sexual reproduction stages, whereas ultraviolet radiation and blue light never resulted in hypnozygote formation. Detailed mechanisms of recognition between the compatible filaments are still unknown; apomixis and/or heterothallism might be an explanation for the low success rate in sex induction.
\end{abstract}

Key words: apomixis, conjugation, polyploidy, Zygnematophyceae

\section{Introduction}

Although occurring worldwide and commonly found in various water bodies, the freshwater green alga Spirogyra (Zygnemataceae, Streptophyta) has been subject to only a few investigations in the past concerning its life cycle, morphology and ecology (e.g. Allen 1958; Hoshaw et al. 1985; BERRY \& LEMBi 2000; Hainz et al. 2009). Due to its spirally coiled, parietal chloroplasts, the genus is easily recognized. Therefore, genus distribution is well recorded (Hoshaw \& McCOURT 1988; Hainz et al. 2009), which, however, does not apply for species distribution. According to traditional identification keys, reproductive stages which are rarely found in nature are required for species identification. McCourT et al. (1986) reported from large scale field collections that they observed these stages in only $10 \%$ out of $632 \mathrm{Spi}$ rogyra collections.

Within the family of Zygnemataceae, sexual reproduction occurs by means of conjugation.
This unique process involves the differentiation of vegetative cells to gametangia and the fusion of amoeboid gametes either in the conjugation tube, which is formed between the cells or in the "female" gametangium. The gametal fusion results in a dormant stage, the so-called hypnozygote or zygospore, which is able to survive unfavourable environmental conditions. In some species, asexual reproduction stages like aplanospores, parthenospores or akinetes do occur. In the most recent worldwide Zygnematalean flora of KADLUBOWSKA (1984), 381 Spirogyra species are listed, based on morphological traits like cell width, number of chloroplasts, type of cross wall, type of reproduction, formation of conjugation channels, shape of gametangia and as key characteristics for species delineation shape, pigmentation, dimensions, and sculpturing of ripe hypnozygotes. Taking into account the infrequent in situ observations of hypnozygotes, which are essential for species identification, there is an obvious need to induce sexual reproduction in the laboratory under de- 
fined conditions (GROTE 1977; SimONS et al. 1984; Yoon et al. 2009). This is also of importance for scrutinizing the traditional species concept, and for implementing the taxon into biomonitoring surveys. Czurda (1933) was the first one who performed a broad study to trigger conjugation in Spirogyra varians (Hassall) KÜtzing. CzURDA (1933) stated that sexual disposition occurs after a period of intense vegetative growth. He was not able to define clearly the physiological conditions of such a state (he called it "disposition for copulation"), but related it to a critical $\mathrm{pH}$ range, which the cells have to pass through. He also found that these $\mathrm{pH}$ values varied for each species, presumably according to the different ecological demands of the organisms. The direct influence of other external factors, such as nutrient depletion, was excluded by him as well as the existence of an inner periodicity of the conjugation process. ALLEN (1958) investigated the complete life cycle of several strains of a homothallic clone of Spirogy$r a$ and developed a standard technique to induce conjugation and zygote formation at will. AlLEN (1958) disbelieved the $\mathrm{pH}$ optimum to be the only external factor and established a quantitative relationship between irradiance supply and the occurrence of sexual stages above a certain minimum of light. Later on, Grote (1977) induced conjugation and spore formation in Spirogyra majuscula KÜTZING in a growth medium without any nitrogen supply. Further, she could not find certain vegetative and generative $\mathrm{pH}$ optima. Subsequent studies emphasized the role of nitrogen depletion and light as key factors to initiate the sexual phase in Spirogyra (Yamashita \& SASAKI 1979; SimONS et al. 1984). SimONs et al. (1984) were able to induce formation of mature hypnozygotes in 31 species, which represented $40 \%$ of the total number of Spirogyra species described in the Netherlands at that time. The important role of nitrogen depletion for the onset of sexual reproduction was confirmed by the work of DeLl'Uomo \& MASI (1985), who studied a community of Zygnemataceae in nature during one year. The impact of light was stressed by KadLuBowsKa (1984), who did not observe conjugation in Spirogyra fluviatilis HILSE until the algae reached the water surface. Very recently, IKEGAYA et al. (2012) succeeded in induction of conjugation in Spirogyra castanacea Couch clones; growth on agar plates and not nitrogen depletion was identified as trigger.

Based on the aforementioned research, the aim of the present study was to examine multi- ple Spirogyra strains with regard to potential key factors for the artificial induction of conjugation and zygote formation. Various culture conditions were tested, with a focus on nutrient depletion, and both light quality and quantity. Successfully obtained hypnozygotes were then used for species identification. Furthermore, environmental data from field sampling of mating and vegetative Spirogyra populations were analysed and compared to the results of the laboratory experiments.

\section{Materials and Methods}

Spirogyra strain collection. Material originated from various Austrian sampling sites and from Germany, Croatia and Egypt (HaInz et al. 2009). Strains were isolated and then cultivated in Erlenmeyer flasks with Desmids medium (Kusel-Fetzmann \& Schagerl 1993) at $18{ }^{\circ} \mathrm{C}$ and a light:dark cycle of $16: 8 \mathrm{~h}$ (PAR of $15 \mu \mathrm{mol}$ photons. $\left.\mathrm{m}^{-2} \cdot \mathrm{s}^{-1}\right)$. Composition of culture media used for experiments and detailed information on the experimental design will be provided upon request. Several different techniques of precultivating the algal strains were applied in order to obtain luxuriant vegetative growth before starting the mating induction experiments. White light was provided by cool white fluorescent tubes (either Philips TLD 36W/33 or Osram FQ 39W/840 LUMLUX Cool White) and in certain cases the precultures were stored in a SANYO MLR-350 versatile environmental chamber.

Mating induction experiments. A total of 95 Spirogy$r a$ strains were tested in multiple experimental setups. Different abiotic parameters were combined and modified to induce sexual reproduction. For this purpose, the precultivated material was transferred into small sterile plastic petri dishes of $55 \mathrm{~mm}$ diameter. Nutrient composition of the medium, light intensity, light quality, light cycle, $\mathrm{pH}$ and temperature were considered as potential key parameters. Three types of culture media were used: (1) organic media, which contained soil extract or bog water; (2) inorganic media of clearly defined composition; (3) autoclaved water originating from sampling sites, diluted to 50\% with Milli Q-water (Millipore Company). Either liquid media or media solidified with $1.5-3 \%$ agar (w:w) were used. White light was provided by cool white fluorescent tubes as aforementioned. The SANYO MLR-350 versatile environmental chamber was used in some experiments. The light:dark cycle was 16:8 h, 13:11 h, or 24:0 h. Additional varicoloured light was provided either by Philips 60W spot lights or by red, green and blue foil, which was filtering the white light emitted from Voltolux 40W standard incandescent lamps. Additional UV light was provided by $300 \mathrm{~W}$ Osram Ultra-Vitalux sunlamps, which emitted irradiances similar to that 
of natural sunlight (spectra will be provided upon request). The light intensity was measured with the Skye Quantum Sensor SKP 215/S and arbitrarily divided into three categories: $(1) \leq 30 \mu \mathrm{mol} \mathrm{m}{ }^{-2} \cdot \mathrm{s}^{-1}$ (low); (2) > 30 to $\leq 70 \mu \mathrm{mol} \mathrm{m}{ }^{-2} \cdot \mathrm{s}^{-1}$ (medium); and (3) $>70 \mu \mathrm{mol}$ $\mathrm{m}^{-2} \cdot \mathrm{s}^{-1}$ (high), with its maximum at about $160 \mu \mathrm{mol}$ photons $\mathrm{m}^{-2} \cdot \mathrm{s}^{-1}$. In case of higher light intensities, the chloroplasts were contracting rapidly, bleaching or changing their colour to brownish-black. $\mathrm{pH}$ was determined with a Metrohm AquatrodePlus combined $\mathrm{pH}$ glass electrode using the Metrohm PC Control Titrando sample processor and software. The petri dishes were regularly checked by means of a stereo microscope in order to find out whether conjugation or zygote formation had occurred or not.

Species identification. Material was examined with a Reichert-Jung Polyvar microscope or with a Zeiss Axio Imager A1 microscope. Digital imaging was done using Olympus cell ${ }^{\wedge} \mathrm{F}$ and analySIS 3.0 software. In certain cases, hypnozygotes were treated with $5 \% \mathrm{KOH}$ in $80 \%$ ethanol for the purpose of dissolving the cell content. The remaining spore walls were then centrifuged and rinsed in ethanol and distilled water. Subsequently, the hypnozygotes were put on a slide and embedded in glycerine (KADLUBOWSKA 1984). This procedure should enhance the sculptures of the spore walls. Some hypnozygotes were fixed in ethanol or Strasburger solution and treated mechanically in an attempt to separate the spore wall layers: the hypnozygotes were put on a slide and pressed slightly while moving the cover glass (SimONs et al. 1982). Species identification was carried out using the three monographs of TRANSEAU (1951), RandHAwa (1959), and KadLubowsKa (1984).

Statistics. In order to compare sampling sites where

Table 1. Standardized canonical discriminant function coefficients discriminating the two groups "vegetative" and "conjugating" sorted in descendent order.

\begin{tabular}{lc}
\hline variable & $\begin{array}{l}\text { Standardized } \\
\text { coefficient }\end{array}$ \\
\hline $\operatorname{lnNP}$ & 2.827 \\
lnPtot & 2.191 \\
lnNO $-\mathrm{N}$ & -1.504 \\
Cond & -0.692 \\
$\mathrm{pH}$ & 0.665 \\
$\operatorname{lnCa}$ & 0.524 \\
$\operatorname{lnSRP}$ & -0.384 \\
$\mathrm{Temp}$ & -0.181 \\
$\ln \mathrm{Mg}$ & -0.147 \\
$\ln \mathrm{NH}_{4}-\mathrm{N}$ & -0.107 \\
$\mathrm{Alk}$ & -0.047 \\
\hline
\end{tabular}

conjugation occurred and sites with only vegetative populations, environmental data from 137 Spirogyra locations in Central Europe were used. For detailed information on the sampling methods and the water analyses procedures see HAINZ et al. (2009). Statistical analyses were done with the SigmaPlot SPW12 and with the IBM SPSS Statistics 20.0 software packages. If necessary, data were ln-transformed to achieve normal distribution, and afterwards standardized to zero means-unit variance. T-tests were chosen to prove significant differences and a linear discriminant analysis (LDA) was performed to find environmental conditions responsible for induction of conjugation in the field $(2$ groups $=$ vegetative, conjugating $)$.

\section{Results}

The analyses of the environmental data did not display any significant differences between sites where conjugation was observed and sites with only vegetative Spirogyra populations (Figs 1-3). Spirogyra occurrences covered a broad range of environmental conditions. $\mathrm{NO}_{3}-\mathrm{N}$ was between below the detection limit and around $20 \mathrm{mg} \cdot \mathrm{l}^{-1}$, $\mathrm{NH}_{4}-\mathrm{N}$ covered a range between 1 and about 1300 $\mu \mathrm{g} .1^{-1}$, SRP was found below detection limit and 1.4 mg. $\mathrm{l}^{-1}$ (Fig. 1). $\mathrm{pH}$ was between 6.2 and 9.1 and total alkalinity ranged from 0.6 to 7.9 mval. $^{-1}$ (Fig. 2). Water temperature was between around 8 and $30{ }^{\circ} \mathrm{C}$, conductivity ranged from around 70 to $1500 \mu \mathrm{S} . \mathrm{cm}^{-1}$ (Fig. 3). A LDA based on field data resulted in a significant model $(\mathrm{r}=0.412$; $p=0.037$; Wilk's Lambda $=0.831)$ with $78 \%$ of the cases placed in the correct group (Fig. 4). Key variables for discriminating the two groups "vegetative" and "conjugating" were $\mathrm{NO}_{3}-\mathrm{N}$ depletion, elevated total phosphorus amounts and a high N:P ratio (Table 1). Moreover, elevated $\mathrm{pH}$ and decreased conductivity seemed to promote conjugation.

In the laboratory, about 681 different experimental setups were performed (Table 2). Artificial induction of the mating process was finally successful in 9 out of 95 Spirogyra clones. Regardless of the day length, sexual reproduction took place in all three categories of light intensity. Onset of conjugation was observed under white, red, and green light, whereas zygote formation occurred only under white and red light (Table 2). Blue or UV light experiments always yielded negative results. Sexual reproduction under red and green light always occurred in nitrogen depleted media. Under white light, it was mainly observed 


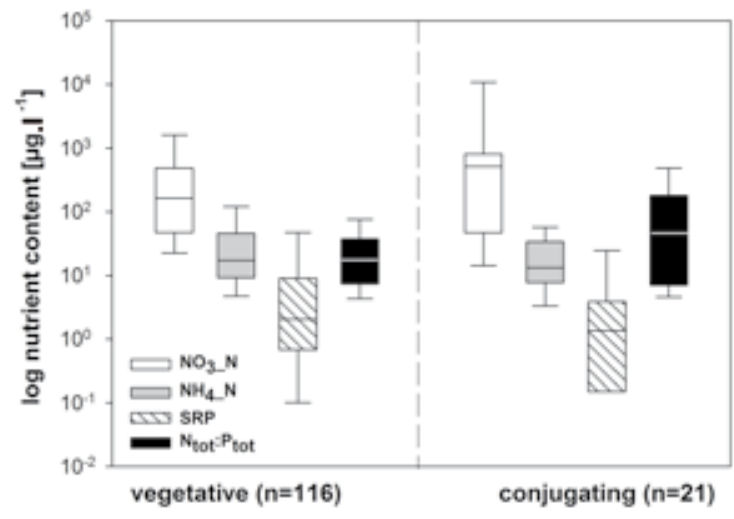

Fig. 1. Nutrient contents of the sampling sites (median boxes with 10-25-75-90 percentiles).

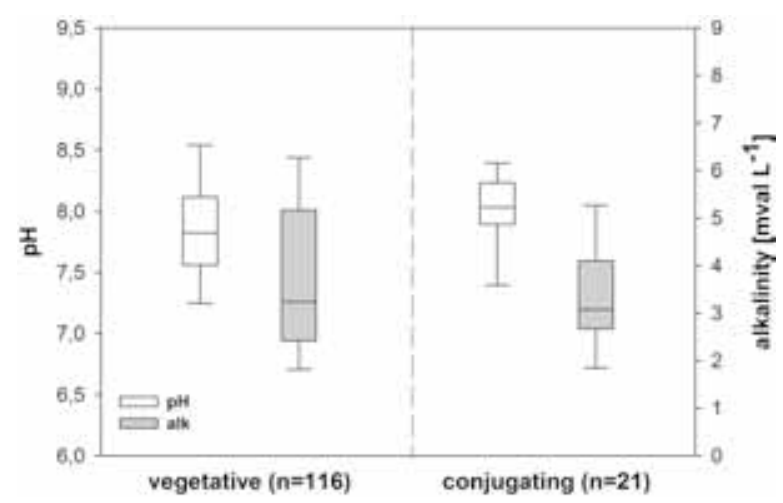

Fig. 2. pH and alkalinity of the sampling sites (median boxes with 10-25-75-90 percentiles).

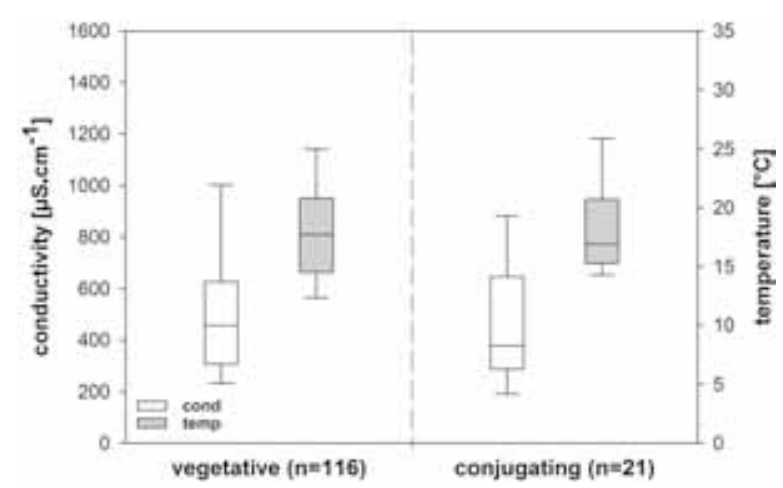

Fig. 3. Conductivity and temperature of the sampling sites (median boxes with 10-25-75-90 percentiles).

in substrates without nitrogen or in phosphorus depleted substrates. A list of species which could artificially be induced to spore formation is given in Table 2. Sexual reproduction in nature was not observed in these cases. It was not possible to identify all strains because of the lack of mature hypnozygotes in some strains (Fig. 5).

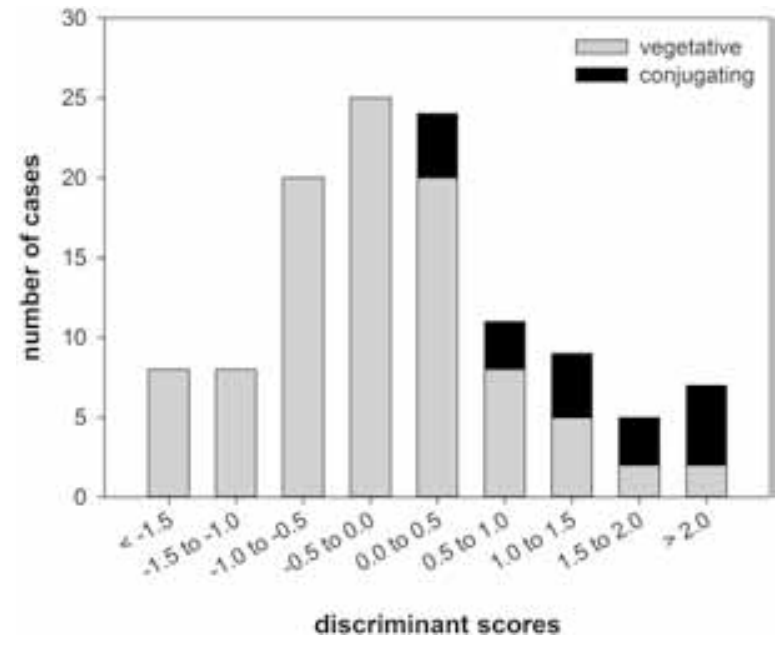

Fig. 4. Results of the linear discriminant analysis. Based on the discriminant function, discriminant scores of the sampling sites were calculated and summarized in classes.

\section{Discussion}

The occurrence of the genus Spirogyra in a broad range of habitats is well documented (HaInZ et al. 2009; McCourt et al. 1986) and also reflected by the results of our environmental data analyses. However, no long-time monitoring of the particular sampling sites was carried out, like it was done in the study of Dell'Uomo \& MAsi (1985) and therefore, no conclusions can be drawn concerning the changes in abiotic environmental conditions which might have caused an onset of sexual reproduction. Regarding this, daily fluctuations of parameters like temperature in algal mats might be of importance (BERRY \& LEMBI 2000; Kato \& Ooshima 1997). Some environmental factors have been reported to induce conjugation of Spirogyra and both nitrogen depletion and light intensity have been regarded as key factors. Our LDA based on obtained field data pointed in the same direction: nitrate deprivation together with elevated organic compounds of $\mathrm{N}$ and $\mathrm{P}$ might promote conjugation. Contrarily to our findings, high temperature was reported as the only important factor to induce conjugation in $\mathrm{Z}$. extenue $\mathrm{J}_{\mathrm{AO}}$ (Kato \& Ooshima 1997). In another study, Kim et al. (2007) were not able to induce conjugation in Zygnema AGARDH artificially.

The present study did not resolve the challenges regarding the induction of the sexual phase in Spirogyra. Even though conjugation and zygote formation in the laboratory indicate a relation to nitrogen depletion, no clear pattern could be found. It seems likely that a certain shift in 

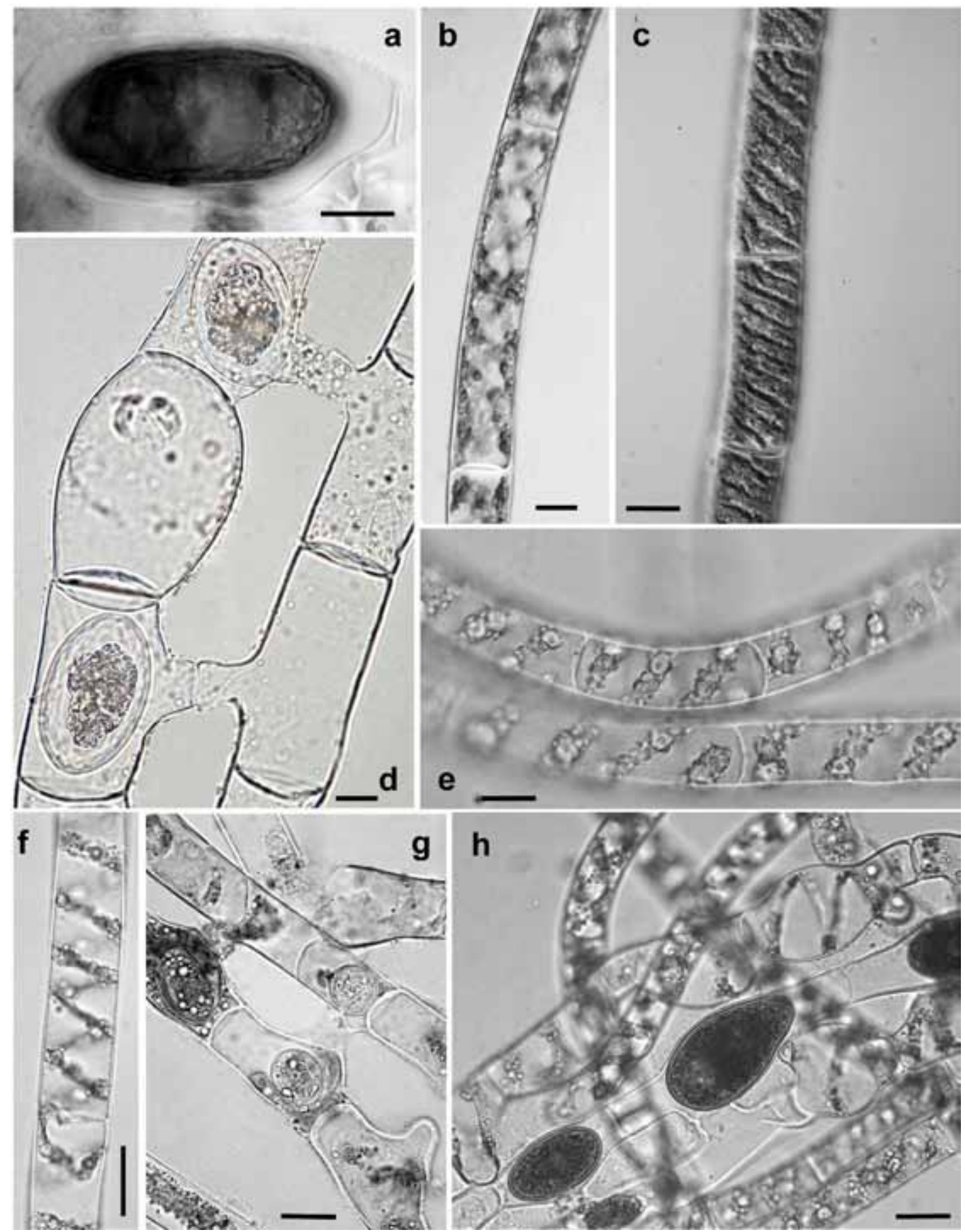

Fig. 5. Spirogyra spp.: (a) S. fluviatilis zygote with brownish colour and corrugated spore wall; (b) S. fluviatilis cell division; (c) S. fluviatilis mature vegetative cell; (d) S. varians with an inflated sterile cell between conjugating cells; (e) vegetative filaments of S. polymorpha; (f) vegetative filament of S. mirabilis; (g) S. mirabilis, formation of parthenospores; (h) S. polymorpha, zygote shape and size differ remarkably within one filament. Scale bar $25 \mu \mathrm{m}$.

nutrient ratios is an important factor in triggering the conjugation process. Our results suggest that sexual reproduction occurs in a wide range of irradiance conditions, which probably reflects the different ecological demands of strains used in the experiments. In cultures, the success of conjugation and zygote formation strongly depends on the type of culture media: BBM medium was successfully used to induce conjugation (Yoon et al. 2009). Compared to Desmids medium, the concentration of nitrate in BBM is about four times lower. Moreover, Simons et al. (1984) found that nitrogen depletion results in the formation of secondary carotenoids and in sporopollenine synthe- 


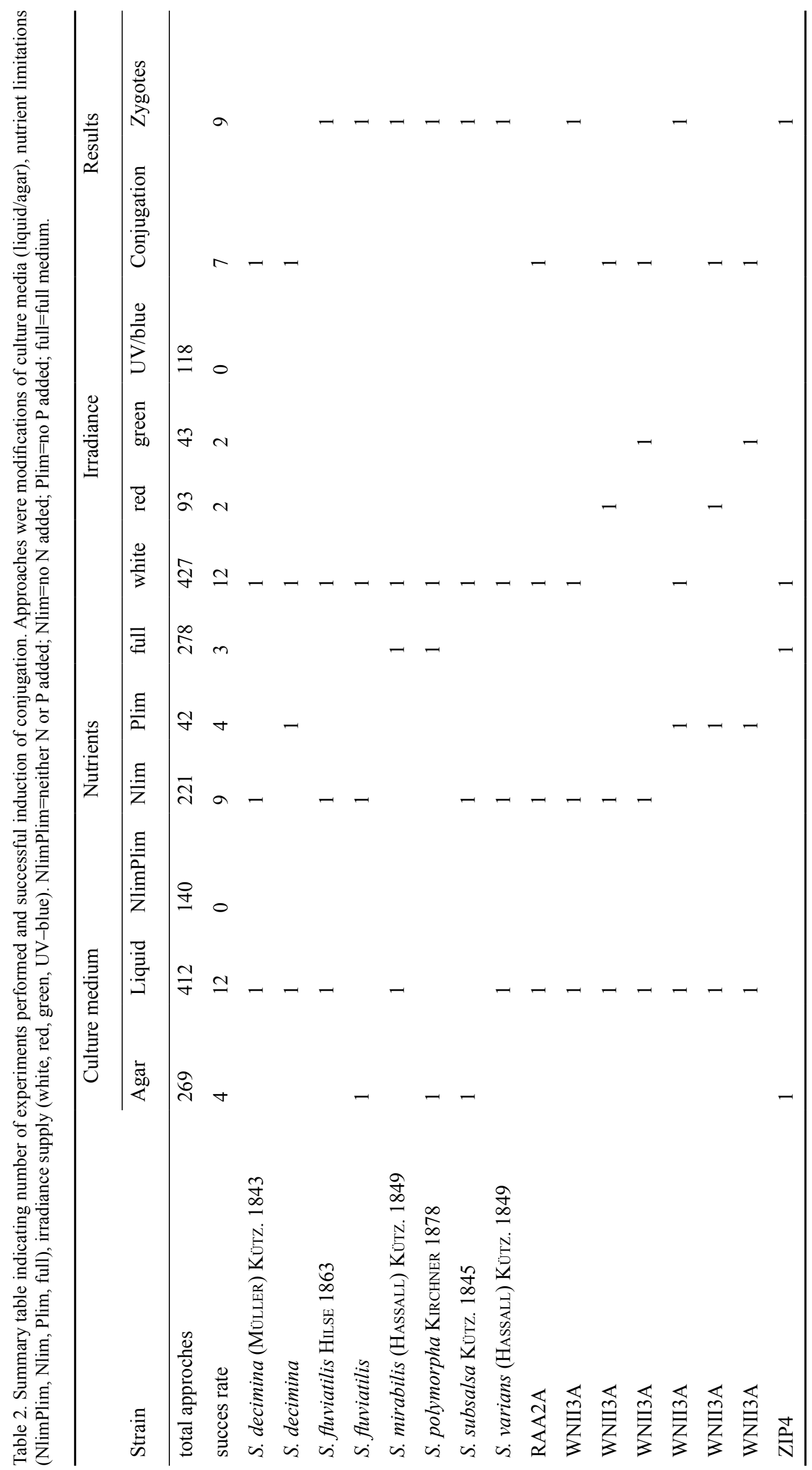


sis, which is part of the hypnozygotes wall. The lack of inorganic nitrogen in the water seems to be involved in the differentiation of gametangia (Simons et al. 1984), which is also supported by the findings of YAMASHITA \& SASAKI (1979), who found a high intracellular $\mathrm{C} / \mathrm{N}$ ratio in generative cells. YAMASHITA \& SASAKI (1979) stated that the accumulation of starch is necessary for the formation of ripe hypnozygotes. During sexual reproduction, the reproductive cells undergo a shift in glycopolysaccharides synthesis as shown for Spirogyra varians (Yoon et al. 2009). Some authors mentioned an onset of sexual reproduction immediately after material was transferred to the laboratory, making it easy to carry out the experiment in a short time (КІм \& Кім 2002; KIM et al. 2007; Yoon et al. 2009).

Studies already conducted with other microalgae e.g., Chlamydomonas reinhardtii DANGEARD, Chlorella sorokiniana SHIHIRA et KRAuss, Haematococcus pluvialis Flotow and Porphyridium purpureum (BORY) DREw et Ross under different light conditions (AI et al. 2008; Posten 2009) have shown that red light promotes the accumulation of algal biomass and the syntheses of matrix polysaccharides (thicker cell walls), which might be seen as a hint for unfavorable growth conditions. Such adverse conditions are a prerequisite for resting stages like hypnozygotes. Another promising approach for sex induction is the modification of culture media. STABENAU \& SÄFTEL (1989) were the first to develop a simple and highly effective method of sexual induction in Mougeotia scalaris Hassal. The conjugation was stimulated by decreasing the concentration of nitrate in the medium, illumination with strong light and aeration of the cultures. PoulíčKová et al. (1997) assumed that conjugation in their Mougeotia (RоTн) AgARDH cultures was caused by nitrogen depletion during desiccation of cultures on petri dishes. Nitrate deprivation seems also to play a key role in induction of gametangia formation of diatoms (PouLíčKovÁ \& MANN 2008) and other desmids like Closterium Nitzsch ex RaLfs (ICHIMURA 1971; TsUCHIKANE et al. 2012).

What could be reasons for the low success in inducing the generative process? Yoon et al. (2009) stated that cultures appeared to loose the ability of conjugation soon after they adapt to the culture conditions. This phenomenon could also be connected to apomixis or apomeiosis, which was already proved for cultivated rhodophyte Caloglossa monosticha KaMiYA (KAMIYA \& WeST
2008). Another explanation might be heterothallism, although to date no evidence for heterothallism exists within this taxon. Interestingly, a few cases of this phenomenon in the family of Zygnemataceae have been observed so far, e.g. in some Zygnema species (Hoshaw 1968). Furthermore, it is possible that sexual reproduction was lost in some Spirogyra strains (apomictic groups), or in polyploid variants belonging to the same species complex (KamiYa \& WeSt 2008). Apomixis is widespread and strongly associated with polyploidy in ferns (Lovis 1977; WAGNER \& WAGNER 1980; PARK \& KATO 2003). In flowering plants, apomixis is also frequently seen in polyploids, and apomictic plants usually produce both asexually and sexually derived embryos (RichaRDS 2003). For Spirogyra, Allen (1958) isolated three clones of significantly different cell width from a single Spirogyra strain indicating different ploidal stages; all three strains conjugated in a similar manner. Also Hoshaw et al. (1985) observed ploidal changes in a clonal culture of Spirogyra communis (HASSAL) KÜTZING.

The few examples of polyploidal clones and the low success rate of inducing the reproductive stages strongly suggest scrutinizing the traditional species concept. Ploidal variants of the same clone change their morphology and most probably also their autecology. Here, an alternative species concept has to be applied considering also ploidal diversity. HALKETT et al. (2005) in their study of population genetics suggest the use of genetic markers in combination with statistic tools to estimate the rate of recombination in a population of partially clonal organisms. Strictly asexual lineages are generally believed to have a short evolutionary age. Interestingly, Spirogyra shows a high evolutionary rate, but a long evolutionary history (CHEN \& SCHAGERL 2012).

The low number of useful morphological characters suggests a small diversity within this genus. This was however refuted by the very recent study of CHEN et al. (2012), who found the genetic distance within the genus Spirogyra exceeding the distances within any other genus of the remaining Zygnemataceae included. CHEN \& SCHAGERL (2012) found that about half of the sequenced clones have lost the 1506 group I intron forming a long-branched group within the genus. In the near future, some of these gaps will hopefully be filled by combining various sequence comparisons with traditional characters. Moreover, single-cell PCR (AUINGER et al. 2008) of 
hypnozygotes would add essential information about the suitability of zygote ultrastructure on Spirogyra species delineation.

\section{Acknowledgements}

This study is part of the FWF project P18465-B03. We gratefully acknowledge Roland Hainz and Martin Gruber (University of Vienna) for doing part of the sampling and laboratory work. Uta Raeder, Viktoria Tscherne (Limnologische Station Iffeldorf - TU München), Ulf Karsten, Henning Baudler, Jana Wölfel (Insitut für Biowissenschaften - University of Rostock), Dieter Hanelt, Ludwig Kies (Fachbereich Biologie - University of Hamburg) kindly supported the collections in Germany.

\section{References}

AI, W.; GuO, S.S.; GaO, F.; TANG, Y.-K. \& Qin, L.F. (2008): Study of Selecting on Light Source Used for Micro-algae Cultivation in Space. In: St.-MAurice, J.-P. (ed.): 37th COSPAR Scientific Assembly. - 410 pp., Montréal, Canada.

Allen, M.A. (1958): The biology of a species complex in Spirogyra [PhD thesis]. - 240 pp., Indiana University, Bloomington.

Auinger, B.M.; Pfandl, K. \& Boenigk, J. (2008): Improved Methodology for Identification of Protists and Microalgae from Plankton Samples Preserved in Lugol's Iodine Solution: Combining Microscopic Analysis with Single-Cell PCR. - Applied and Environmental Microbiology 74: 2505-2510.

Berry, H.A. \& LemBi, C.A. (2000): Effects of temperature and irradiance on the seasonal variation of a Spirogyra (Chlorophyta) population in a midwestern lake (U.S.A.). - Journal of Phycology 36: 841-851.

Chen, C.; Barfuss, M.H.J.; Pröschold, T. \& SchaGERL, M. (2012): Hidden genetic diversity in the green alga Spirogyra (Zygnematophyceae, Streptophyta). - BMC Evolutionary Biology 12: 77.

Chen, C. \& Schagerl, M. (2012): Slow evolution of 1506 group I intron in Spirogyra LiNK 1820 (Zygnematophyceae, Streptophyta), a fast evolving lineage in the Zygnemataceae. - Fottea 12: $255-272$.

Czurda, V. (1933): Experimentelle Analyse der kopulationsauslösenden Bedingungen bei Mikroorganismen - 1. Untersuchungen an Algen (Spirogyra, Zygnema und Hyalotheca). - Beihefte zum Botanischen Centralblatt 51: 711-761.

Dell'Uomo, A. \& Masi, M.A. (1985): Sexual reproduction in nature of some filamentous conjugating algae. - Nova Hedwigia 41: 177-199.
Grote, M. (1977): Über die Auslösung der generativen Forpflanzung unter kontrollierten Bedingungen bei der Grünalge Spirogyra majuscula. - Zeitschrift für Pflanzenphysiologie 83: 95-107.

Hainz, R.; Wöber, C. \& Schagerl, M. (2009): The relationship between Spirogyra (Zygnematophyceae, Streptophyta) filament type groups and environmental conditions in Central Europe. Aquatic Botany 91: 173-180.

Halkett, F.; Simon, J.C. \& Balloux, F. (2005): Tackling the population genetics of clonal and partially clonal organisms. - Trends in Ecology \& Evolution 20: 194-201.

Hoshaw, R.W. (1968): Biology of filamentous conjugating algae. - In: JACKSON, D.F. (ed.): Algae, Man and the Environment. - pp. 135-184, Syracuse Univ. Press, Syracuse, New York.

Hoshaw, R.W. \& McCourt, R.M. (1988): The Zygnemataceae (Chlorophyta): a twenty-year update of research. - Phycologia 27: 511-548.

Hoshaw, R.W.; Wang, J.-C.; McCourt, R.M. \& Hull, H.M. (1985): Ploidal changes in clonal cultures of Spirogyra communis and implications for species definition. - American Journal of Botany $72: 1005-1011$.

ICHIMURA, T. (1971): Sexual cell division and conjugation-papilla formation in sexual reproduction of Closterium strigosum. - In: Nishizawa, K. (ed): Proceedings of the 7 th International seaweed symposium. - pp. 208-214, University of Tokyo Press, Tokyo.

KadlubowsKa, J.Z. (1984): Conjugatophyceae I - Zygnemales. - In: Ettr, H.; Gerloff, H.; Heynig, H. \& Mollenhauer, D. (eds): Süßwasserflora von Mitteleuropa, Chlorophyta VIII. - pp. 1-531, Gustav Fischer Verlag, Stuttgart, New York.

Kato, S. \& Ooshima, K. (1997): The factor for inhibition of sexual reproduction in Zygnema extenue Jao (Zygnematales, Chlorophyceae). - Japanese Journal of Phycology 45: 1-4.

KamiYA, M. \& WeSt, J.A. (2008): Origin of apomictic red algae: Outcrossing studies of different strains in Caloglossa monosticha (Ceramiales, Rhodophyta). - Journal of Phycology 44: 977-984.

KIM, Y.H. \& KIM, G.H. (2002): A biology of the green algae, Spirogyra. - pp. 1-230, Gaesin, Chungju.

Kim, G.H.; Yoon, M.C.; West, J.A.; Klochova, T.A. \& KIM, S.H. (2007): Possible surface carbohzdrates involved in signaling during conjugation process in Zygnema cruciatum monitored with FITC-lectins (Zygnemataceae, Chlorophyta). Phycological Research 55: 135-142.

Kusel-Fetzmann, E. \& Schagerl, M. (1993): Verzeichnis der Sammlung von Algenkulturen an der Abteilung für Hydrobotanik am Institut für Pflanzenphysiologie der Universität Wien. Phyton 33: 209-234. 
Lovis, J. D. (1977): Evolutionary patterns and processes in ferns. - Advances in Botanical Research 4: $229-415$.

McCourt, R.M.; Hoshaw, R.W. \& WAnG, J.-C. (1986): Distribution, morphological diversity and evidence for polyploidy in North American Zygnemataceae (Chlorophyta). - Journal of Phycology 22: 307-315.

PARK, C.-H. \& Kato, M. (2003): Apomixis in the interspecific triploid hybrid fern Cornopteris christenseniana (Woodsiaceae). - Journal of Plant Research 116: 93-103.

PoulíčKová, A.; Zizka, Z.; Hasler, P. \& Benada, O. (2007): Zygnematalean zygospores: morphological features and use in species identification. - Folia Microbiologica 52: 135-145.

PoulíčKovÁ, A. \& Mann, D.G. (2008): Autogamous auxosporulation in Pinnularia nodosa (Bacillariophyceae). - Journal of Phycology 44: $350-363$.

Posten, C. (2009): Design principles of photo-bioreactors for cultivation of microalgae. - Engineering in Life Science 9: 165-177.

Pringsheim, E.G. (1946): The biphasic or soilwater culture method of growing algae or flagellata. Journal of Ecology 33: 193-204.

RandHawa, M.S. (1959): Zygnemaceae. - pp. 1-478, Indian Council of Agricultural Research, New Delhi.

Richards, A. J. (2003): Apomixis in flowering plants: an overview. - Philosophical Transactions of the Royal Society B: Biological Sciences 358: 1085-1093.

Rosello Sastre, R.R.; Csögör, Z.; Perner Nochta, I.; Fleck-Schneider, P. \& Posten, C. (2007): Scaledown of microalgae cultivations in tubular photo-bioreactors - A conceptual approach. - Journal of Biotechnology 132: 127-133.

Simons, J.; Van Beem, A.P. \& De Vries, P.J.R. (1982): Structure and chemical composition of the spore wall in Spirogyra (Zygnemataceae, Chlorophyceae). - Acta Botanica Neerlandica 31: 359-370.

Simons, J.; Van Beem, P. \& De Vries, P.J.R. (1984): Induction of conjugation and spore formation in species of Spirogyra (Chlorophyceae, Zygnematales). - Acta Botanica Neerlandica 33: 323-334.

Stabenau, H. \& Säftel, W. (1989). Induction of conjugation in Mougeotia. - Canadian Journal of Botany 67: 2217-2218.

Tennessen, D.J.; SingsaAs, E. L. \& Thomas, D.S. (1994): Light-emitting diodes as a light source for photosynthesis research. - Photosynthesis Research 39: 85-92.

Transeau, E.N. (1951): The Zygnemataceae (freshwater conjugate algae) with keys for the identification of genera and species, and seven hun- dred eighty-nine illustrations. - pp. 1-327, The Ohio State University Press, Columbus.

Tsuchikane, Y.; Tsuchiya, M.; Hindak, F.; Nozaki, H. \& Sекімото, H. (2012). Zygospore formation between homothallic and heterothallic strains of Closterium. - Sexual Plant Reproduction 25:1-9.

Ueno, T. \& SASAKI, K. (1978): Light dependency of the mating process in Closterium acerosum. - Plant and Cell Physiology 19: 245-252.

Wagner, W. H.; JR. \& Wagner, F. S. (1980): Polyploidy in pteridophytes. - In: LewIS, W. H. (ed.): Polyploidy. - pp. 199-214, Plenum Press, London.

Yamashita, T. \& SASAKI, K. (1979): Conditions for the induction of the mating process and changes in contents of carbohydrates and nitrogen compounds during the mating process of Spirogyra. - Journal of the Faculty of Science Hokkaido University Series 5: 279-287.

Yoon, M.; KIM, K.M. \& KIM, G.H. (2009): Conjugation process in Spirogyra varians monitored with FITC/lectins (Zygnemataceae, Chlorophyta). - Algae 24: 39-45.

(C) Czech Phycological Society (2013)

Received June 19, 2012

Accepted October 8, 2012 